\title{
Influence of urban morphology and sea breeze on hot humid microclimate: the case of Colombo, Sri Lanka
}

\author{
Rohinton Emmanuel ${ }^{1, *}$, Erik Johansson ${ }^{2}$ \\ ${ }^{1}$ Dept. of Architecture, University of Moratuwa, Moratuwa 10400, Sri Lanka \\ ${ }^{2}$ Housing Development \& Management, Lund University, PO Box 118, 22100 Lund, Sweden
}

\begin{abstract}
Urbanisation leads to increased thermal stress in hot-humid climates due to increased surface and air temperatures and reduced wind speed. We examined the influence of urban morphology and sea breeze on the microclimate of Colombo, Sri Lanka. Air and surface temperatures, humidity and wind speed were measured at 1 rural and 5 urban sites during the warmest season. The urban sites differed in their height to width $(\mathrm{H} / \mathrm{W})$ ratio, ground cover and distance to the sea. Intra-urban air temperature differences were greatest during the daytime. A maximum intra-urban difference of $7 \mathrm{~K}$ was recorded on clear days. Maximum temperatures tended to decrease with increasing H/W ratio and proximity to the sea. All urban sites experienced a nocturnal urban heat island (UHI) when the sky was clear or partly cloudy. The temperature differences between sunlit and shaded urban surfaces reached $20 \mathrm{~K}$, which shows the importance of shade in urban canyons (reducing long-wave radiation from surfaces). Within the urban areas, the vapour pressure was high $(>30 \mathrm{hPa})$ and showed little diurnal variation. Wind speeds were low $\left(<2 \mathrm{~m} \mathrm{~s}^{-1}\right)$ and tended to decrease with increasing $\mathrm{H} / \mathrm{W}$ ratio. Shading is proposed as the main strategy for lowering air and radiant temperatures; this can be achieved by deeper canyons, covered walkways and shade trees. It is also suggested to open up wind corridors perpendicular to the sea to facilitate deeper sea breeze penetration.
\end{abstract}

KEY WORDS: Urban geometry · Tropical climate - Climate-sensitive urban design · Urban heat island C Coastal city structure

\section{INTRODUCTION}

The hot-humid tropics are experiencing unprecedented urban growth rates (Emmanuel 2005). It is thought that this period of urban transformation in the hot humid region will be completed in a period of <60 yr (1950-2010) (cf. WCED 1987, Oke et al. 1990/91, Jáuregui 1997).

Environmental changes brought about by urbanisation have been studied by researchers in medicine, agriculture, geography and climatology (cf. Harrison \& Gibson 1976, Lake et al. 1993); however, application of this knowledge in the field of urban planning and design has been limited (see e.g. Eliasson 2000). Problems such as increased energy use in buildings and deteriorating human comfort have received very little attention among urban planners and designers. This is especially the case in tropical cities, where urbanisation is at its peak. Considering the importance of cities in the national economies of developing tropical countries, a deterioration in the quality of life in tropical cities is likely to have an adverse effect on the respective national economies.

\subsection{Urban morphology and climate}

Cities have a nocturnal urban heat island (UHI) which tends to be more intense in the densely built, downtown area than in the suburbs. Traditionally, the thermal properties of building materials were thought 
to be the primary cause for this urban climate anomaly. However, evidence indicating the importance of urban geometry to the creation and the magnitude of the UHI phenomenon began to accumulate in the 1970s. Terjung \& Louie (1973) were among the first to suggest that the urban-rural daytime temperature anomaly is largely attributable to the aspect of vertical surfaces to the sun.

Comparing the UHI effect of thermal properties and urban geometry, Oke (1981) found no significant correlation between types of man-made surfaces and UHI intensity. The only significant difference observed was between man-made and natural surfaces. Thus, concrete surfaces and asphalt paving, brick and concrete block walls, all contribute more or less equally to the problem of urban heat build-up, while treecovered areas show a remarkable reduction in heat build-up. A comparison of nocturnal UHIs and urban geometry showed that UHI intensity increases with increasing height to width (H/W) ratios of street canyons (see e.g. Oke 1981, 1988). However, Oke (1988) argued that non geometrical factors such as heat capacity and anthropogenic heat release may also influence UHI intensities.

Todhunter (1990) took the position that, at the microscale, urban geometry was more important in explaining the spatial-temporal distribution of UHIs than surface materials. However, he argued that both the geometry and surface thermal characteristics played an equal role at the mesoscale.

Arnfield (1990) and Oke et al. (1991) carried out some of the earliest comparisons of the causes of the nocturnal UHI. Their numerical simulation studies concluded, inter alia, that

- Canyon geometry on its own is capable of giving rise to variations in nocturnal cooling which can generate a UHI.

- The magnitude of the UHI also depends on the differences in thermal properties between urban and rural areas. Higher soil moisture (and thus higher heat storage capacity and thermal admittance) makes the rural surroundings less different from urban surfaces. This may explain the lower UHIs found in many tropical cities.

- The presence of clouds, which increase the sky emissivity, results in weaker nocturnal UHIs as well as decreasing differences between different canyon forms.

\subsection{Urban climate anomaly in tropical cities}

Tropical nocturnal UHIs tend to be lower than in temperate climates (Jonsson 2005). Moreover, while the UHIs in temperate climates tend to be greater in the summer than in the winter, the seasonal difference in tropical regions is related to the wet and dry seasons (Arnfield 2003, Jonsson 2005). The nocturnal UHI is strongest during the dry season (e.g. Adebayo 1991, Jáuregui 1997, Jonsson 2005). The main reason is believed to be the smaller urban-rural differences in thermal properties because of more humid rural surroundings (higher humidity increases the heat capacity of soil; see also Oke et al. 1991).

Although the nocturnal UHI is well studied, the daytime urban climate has received less attention. In general, the urban-rural differences are smaller by day than by night, and the city can be either warmer or cooler than the rural surroundings (Arnfield 2003, Emmanuel 2005). Shade can lead to a daytime cool island (Oke et al. 1991, Johansson in press) in deep canyons. In their review of tropical UHI studies, Jonsson (2005) reported both daytime heat and cool island observations.

Hot climates tend to lead to larger intra-urban thermal differences than do cooler climates (Emmanuel 1997). The variation in urban microclimate and its implications on thermal comfort in the hot-humid tropics are discussed in Emmanuel (2005).

\subsection{Aim of the study}

Although the number of UHI studies in tropical cities has increased in recent decades (Arnfield 2003), they are still few compared to the number in temperate climates, especially concerning the influence of urban design on the daytime urban microclimate.

This study empirically examines the microclimate effects of the existing urban morphology of Colombo, Sri Lanka, and highlights some adaptation strategies that could improve the microclimate at street level. This study concentrates on climatic aspects; the effect of the microclimate on human comfort, including the calculation of an outdoor thermal comfort index, is presented in Johansson \& Emmanuel (in press).

\section{STUDY AREA}

The city of Colombo (Fig. 1) is located at $6^{\circ} 54^{\prime} \mathrm{N}$, $79^{\circ} 52^{\prime} \mathrm{E}$ on Sri Lanka's West coast. The municipal area of the city, which had a daytime population of 0.65 million in 2001, is in the center of the largely urbanized Colombo Metropolitan Region (CMR) of 5.3 million inhabitants. The CMR, which covers 3 administrative districts (Colombo in the center, Gampaha to the $\mathrm{N}$ and $\mathrm{E}$, and Kalutara to the $\mathrm{S}$ ) has an $\mathrm{N}-\mathrm{S}$ extent of about $100 \mathrm{~km}$ and extends $40 \mathrm{~km}$ inland. 


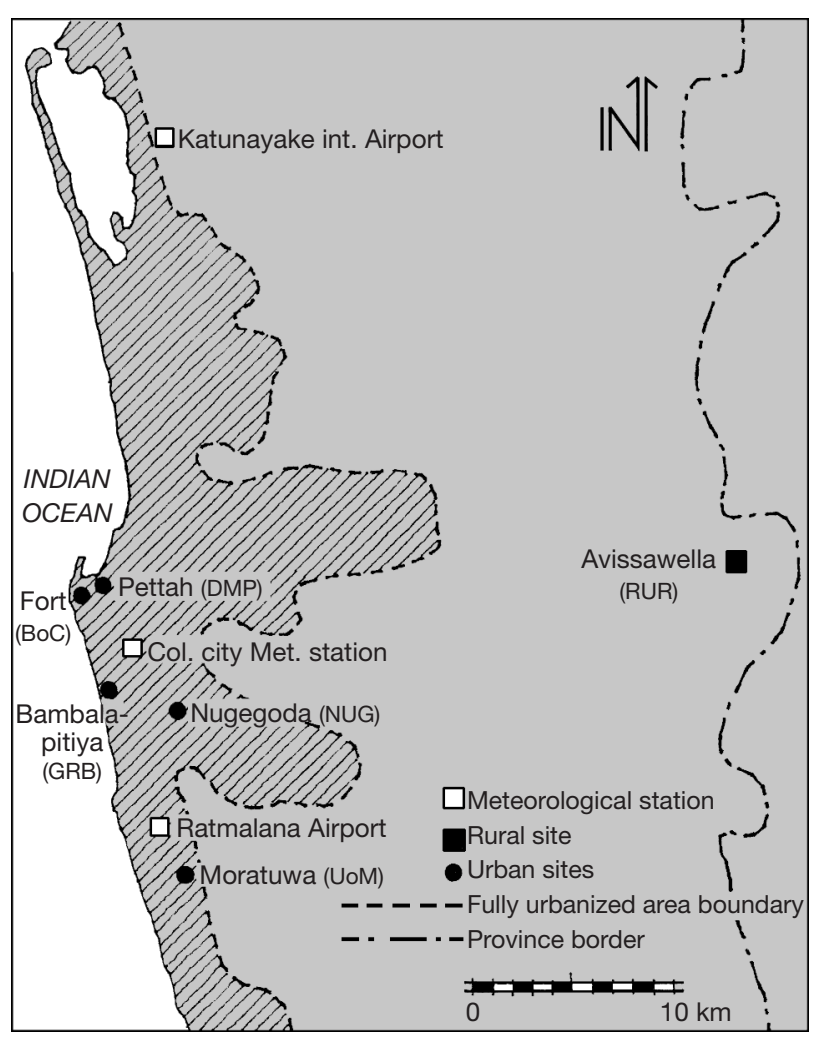

Fig. 1. Colombo $\left(6^{\circ} 54^{\prime} \mathrm{N}, 79^{\circ} 52^{\prime} \mathrm{E}\right)$ with suburbs and locations of the measurement sites and official weather stations

\subsection{Urban structure}

Colombo has low building density with high green cover and many low-rise buildings. Due to the natural limits to the West (Indian Ocean) and the East (extensive marshlands), the city has generally grown in a $\mathrm{N}-\mathrm{S}$ direction along the national highways (Fig. 1). The combination of wide streets and low-rise buildings results in low $\mathrm{H} / \mathrm{W}$ ratios, except in the central business district (the old colonial Fort area) and the old commercial quarters (Pettah). The former is characterized by high-rise buildings with some very high tower buildings, while the latter is characterized by a continuous built up street frontage of medium-rise buildings ( 3 to 4 stories) on narrow streets. The main transport axis in the city, Galle Road, runs N-S some $200 \mathrm{~m}$ parallel to the coast and is bordered by medium-rise buildings along much of its length within the city.

The ground cover and amount of vegetation vary greatly between neighborhoods, from an almost complete canopy cover in exclusive residential neighborhoods to paved/asphalted streets with few trees in less affluent sectors. The city has only a few parks. The outskirts of Colombo can be characterized as semi-urban; buildings are mainly positioned along the roads and the areas in between consist of agricultural land, including paddy and cash crop fields, marshes, open areas and water bodies.

\subsection{Climate conditions ${ }^{1}$}

Colombo is a lowland region with a typically hothumid climate that is affected by the seasonal wind reversal of the Asiatic monsoon. The monsoon blows from the SW from late May to late September and the NE from late November to mid February. Air temperature and humidity are high throughout the year (see Fig. 3). Wind speeds are low, especially during the inter-monsoon periods of March to April and October to November. The annual rainfall is $2300 \mathrm{~mm}$, with 2 seasonal peaks (see Fig. 3). Solar radiation is intense under clear sky conditions. However, there is a high probability of cloud development, especially during the afternoon. The mean daily sunshine duration varies between $5 \mathrm{~h}$ in June and $9 \mathrm{~h}$ in February.

\section{METHODS}

\subsection{Selection of measurement sites}

Based on the geographical features of the city, we predicted that the main variables influencing the urban climate in the city of Colombo would be morphology, land cover characteristics and the distance from the sea. We selected 6 measurement sites to reflect these variables, 5 within the city of Colombo and its suburbs and 1 rural site (see Fig. 1). The urban sites represent different neighborhoods ranging from dispersed, low-rise suburban areas to densely populated downtown areas and the high-rise business district (Fig. 2). The following land cover classes were studied: buildings, hard surfaces (asphalted roads and paved surfaces) and green cover. Except for the sea, there were no water bodies in the vicinity of the selected sites. The rural site, situated in an agricultural area some $30 \mathrm{~km}$ east of Colombo, was surrounded by rubber plantations. Land cover information for a radius of $200 \mathrm{~m}$ around each site, was obtained from aerial images and Computer Assisted Design (CAD) drawings. The latter consist of polygons which indicate the areas covered by buildings, roads/hard surfaces and water bodies. Information about the vegetation was assessed from aerial photographs. The characteristics of the sites are given in Table 1.

\footnotetext{
1 Based on data from Colombo city station, 1970-2004 (Department of Meteorology, Sri Lanka)
} 

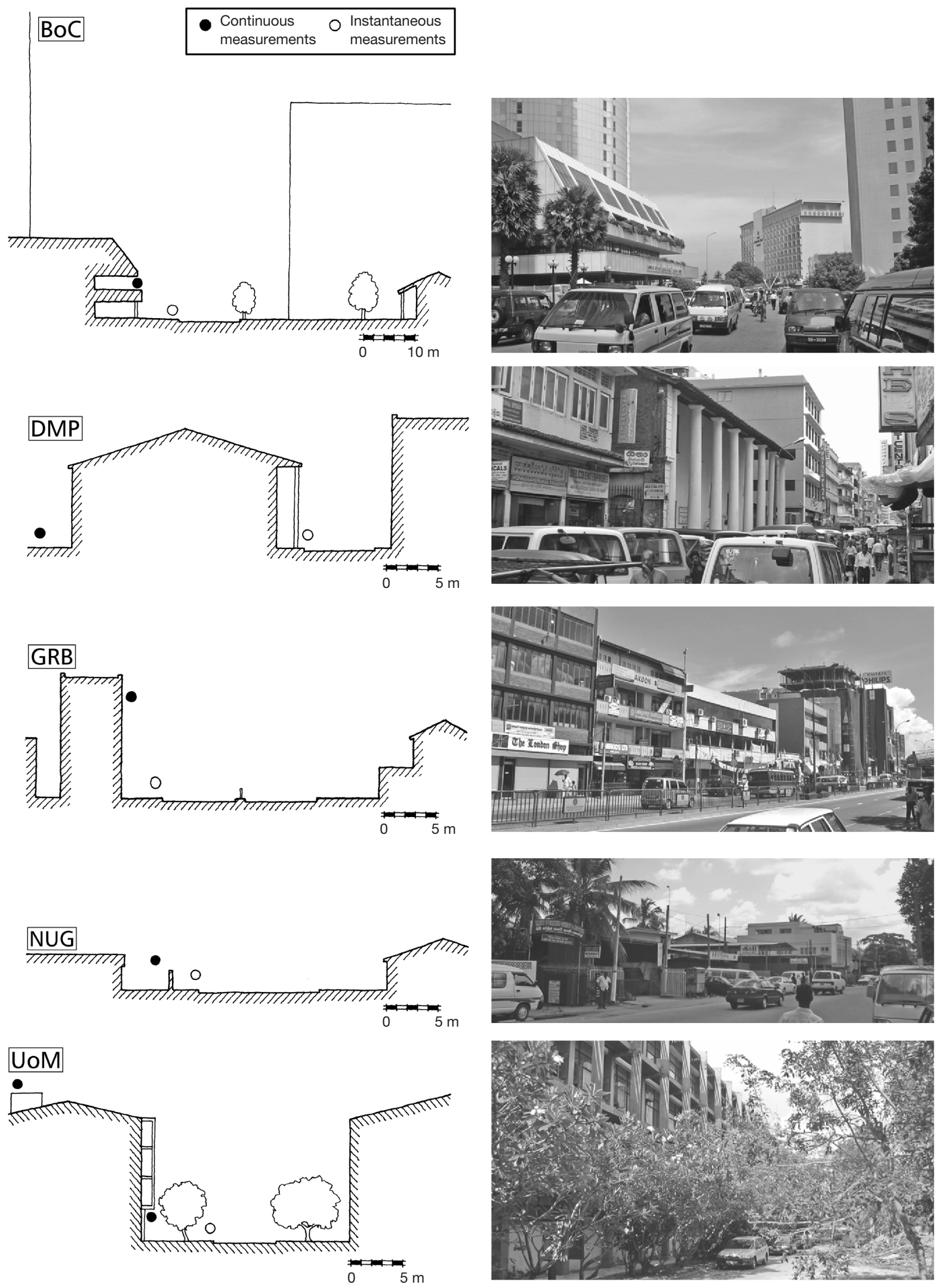

Fig. 2. Positioning of measurement equipment within urban canyons. BoC: Bank of Ceylon, Fort; DMP: Prince Street, Pettah; GRB: Galle Road, Bambalapitiya; NUG: Pagoda Road, Nugegoda; UoM: University of Moratuwa 
Table 1. Land use and ground cover of measurement sites and their surroundings. See Figs. $1 \& 2$ for locations and abbreviations

\begin{tabular}{|c|c|c|c|c|c|c|}
\hline \multirow[t]{2}{*}{ Site } & \multirow{2}{*}{$\begin{array}{c}\text { General } \\
\text { description }\end{array}$} & \multirow{2}{*}{$\begin{array}{l}\text { Land } \\
\text { use }\end{array}$} & \multirow[t]{2}{*}{ Buildings } & \multicolumn{3}{|c|}{ Ground cover $(\%)^{\mathrm{a}}$} \\
\hline & & & & Built-up & $\begin{array}{l}\text { Roads and } \\
\text { paving }\end{array}$ & Green \\
\hline $\mathrm{BoC}$ & $\begin{array}{l}\text { Downtown location, central business } \\
\text { district. Close to sea-shore, some trees }\end{array}$ & $\begin{array}{l}\text { Commercial/ } \\
\text { office }\end{array}$ & $\begin{array}{l}\text { High-rise, } \\
\text { some very } \\
\text { high towers }\end{array}$ & 40 & 55 & 5 \\
\hline DMP & $\begin{array}{l}\text { Downtown location, old commercial } \\
\text { quarters, just E of Fort. Away from } \\
\text { shore, almost devoid of vegetation }\end{array}$ & $\begin{array}{l}\text { Commercial/ } \\
\text { residential }\end{array}$ & $\begin{array}{l}\text { Medium-rise } \\
\text { (3-4 stories) }\end{array}$ & 60 & 40 & 0 \\
\hline GRB & $\begin{array}{l}\text { Commercial sector } \mathrm{S} \text { of Fort, some trees. } \\
\text { Close to sea shore, but buildings act as } \\
\text { a barrier to sea breeze }\end{array}$ & $\begin{array}{l}\text { Commercial/ } \\
\text { office/ } \\
\text { residential }\end{array}$ & $\begin{array}{l}\text { Low- to medium-rise } \\
\text { (1-4 stories })\end{array}$ & 35 & 55 & 10 \\
\hline NUG & $\begin{array}{l}\text { Mixed-residential sector SE of city } \\
\text { centre. Away from sea }\end{array}$ & Residential & Low-rise & 30 & 50 & 20 \\
\hline UoM & $\begin{array}{l}\text { Low-density, suburban location S of city. } \\
\text { Away from sea }\end{array}$ & Institutional & Medium-rise & 20 & 20 & 60 \\
\hline RUR & Rural, inland rubber plantation area & Agricultural & - & $<5$ & 0 & $>95$ \\
\hline
\end{tabular}

Table 2. Street canyons where measurements were taken (for site keys, see Table 1). H/W: height to width ratio; SVF: sky view factor

\begin{tabular}{|c|c|c|c|c|c|c|c|c|c|}
\hline \multirow[t]{2}{*}{ Site } & \multirow[t]{2}{*}{ Type of street } & \multirow[t]{2}{*}{$\mathrm{H} / \mathrm{W}^{\mathrm{a}}$} & \multirow[t]{2}{*}{$\mathrm{SVF}^{\mathrm{b}}$} & \multirow[t]{2}{*}{ Orientation } & \multirow{2}{*}{$\begin{array}{l}\text { Vehicle } \\
\text { traffic }\end{array}$} & \multicolumn{3}{|c|}{ Ground cover } & \multirow{2}{*}{$\begin{array}{l}\text { Distance to } \\
\operatorname{sea}^{\mathrm{d}}(\mathrm{km})\end{array}$} \\
\hline & & & & & & Paving & Road & Green & \\
\hline $\mathrm{BoC}$ & Commercial, medium sized street & 0.8 & 0.49 & $\mathrm{E} / \mathrm{W}$ & Medium & Concrete & Asphalt & Some & 0.2 \\
\hline DMP & Commercial, narrow street & 1.2 & 0.31 & ENE/WSW & Low $^{c}$ & Concrete & Asphalt & None & 0.5 \\
\hline GRB & Commercial, 6-lane highway & 0.3 & 0.65 & NNW/SSE & High & Concrete & Asphalt & Little & 0.3 \\
\hline NUG & $\begin{array}{l}\text { Residential, main road through } \\
\text { neighborhood, medium sized street }\end{array}$ & $\mathrm{t}^{0.1}$ & 0.75 & NNE/SSW & Medium & Asphalt & Asphalt & Little & 4 \\
\hline $\begin{array}{l}\text { UoM } \\
\text { aAppr }\end{array}$ & $\begin{array}{l}\text { Institutional, narrow street } \\
\text { oximate values (average) }\end{array}$ & 0.5 & 0.44 & $\mathrm{E} / \mathrm{W}$ & Low & Concrete & Gravel & Some & 3 \\
\hline \multicolumn{10}{|c|}{ 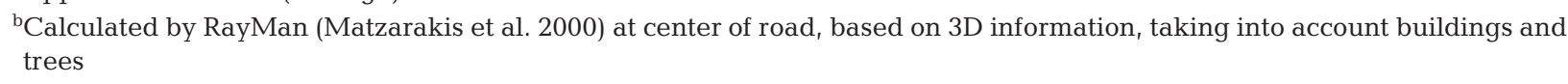 } \\
\hline
\end{tabular}

The ground cover around each measurement site varied, but the surface materials within the urban canyons were similar. With the exception of the University of Moratuwa (UoM) site, which had a graveled road, ground surface materials consisted of asphalted roads and concrete sidewalks. Building facades generally consisted of plastered bricks or concrete blocks. However, urban geometry and distance to the sea varied (Table 2).

\subsection{Field measurements}

Field measurements were carried out during the period of April 30 to May 16, 2003. The measurements were taken during the inter-monsoon period, which is characterized by relatively high temperatures and humidity (Fig. 3) as well as low wind speeds. During the measurement period, the average diurnal temperature and relative humidity measured at the Colombo 

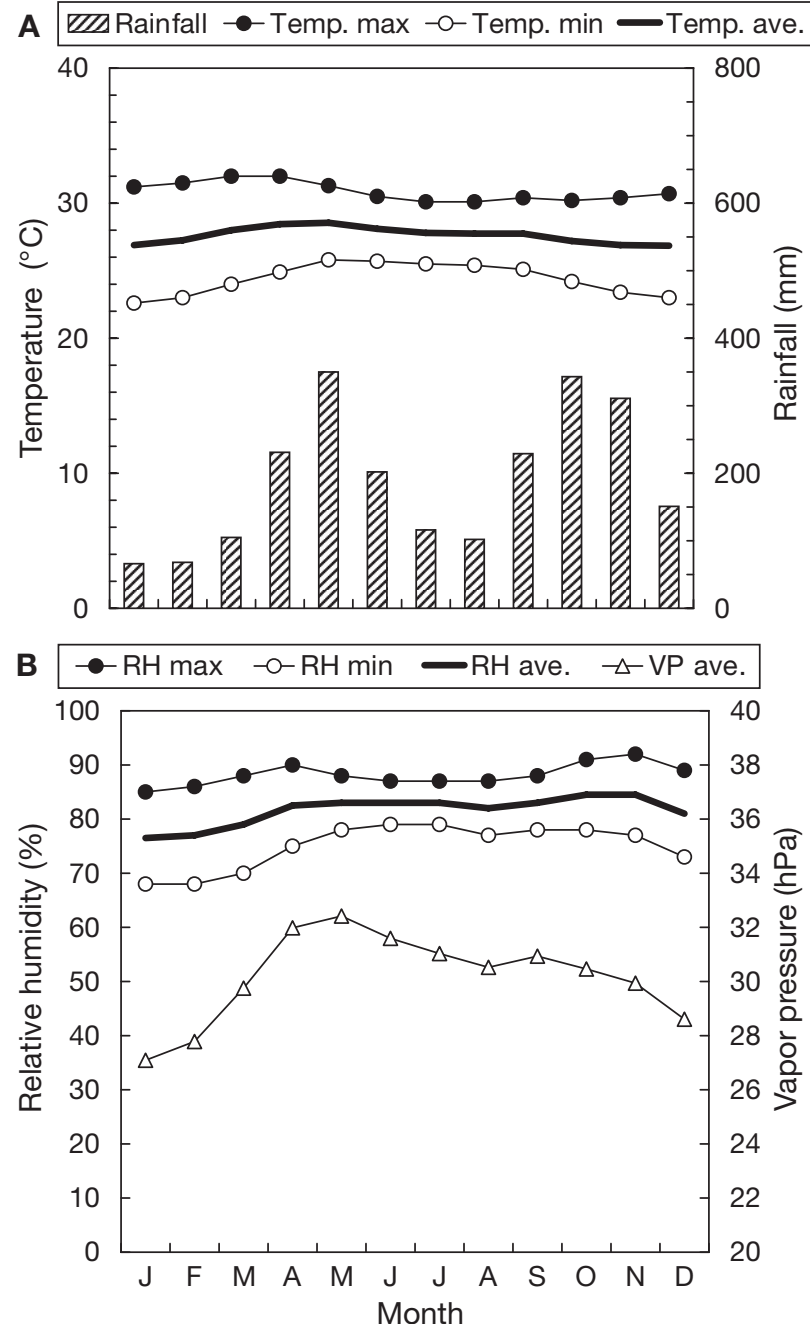

Fig. 3. (a) Monthly mean temperature (maximum, average and minimum) and rainfall. (b) Monthly mean relative humidity (maximum, average and minimum) and vapour pressure. Values based on measurements by Sri Lankan Department of Meteorology for Colombo city weather Stn, 1970-2004. Temp.: temperature; max: maximum; min: minimum; ave.: average (i.e. mean); RH: relative humidity; VP: vapour pressure city weather station varied between 26 and $30^{\circ} \mathrm{C}$ and 75 and $90 \%$, respectively. The total rainfall was $292 \mathrm{~mm}$. These values are very close to the average values for May, thus the weather during the measurement period was representative of the season.

\subsubsection{Fixed stations}

Air temperature and relative humidity within the street canyons were measured continuously. Air temperature, relative humidity and global solar radiation above roof level were also recorded at the UoM site. Fig. 2 shows the positioning of the measurement equipment within the urban canyons. The rural measurements were made in a clearing within a rubber plantation with few built-up areas in the vicinity. The measured parameters and the instruments used are given in Table 3. All the temperature and humidity probes were shielded with white plastic radiation screens. The instruments were calibrated in climate chambers before the commencement of the study and they were calibrated against each other at the end of the measurement period (May 13 to 16, 2003) at the Nugegoda (NUG) site.

Following Oke (2004) temperature and humidity probes should be partitioned as close to pedestrian height as possible and sufficiently away from vertical surfaces. However, this was not possible, for practical (vehicle and pedestrian traffic) and security reasons (risk of theft). Thus, the actual positions in some cases were not ideal (see Fig. 2). However, air temperature differences within an urban canyon are relatively small, except near the canyon surfaces (e.g. Nakamura \& Oke 1988). The probes were located at least $1 \mathrm{~m}$ from the facades at all the sites. In order to complement the continuous measurements, instantaneous measurements of air temperature and relative humidity were taken at pedestrian level at each site during the first week of the measurement period (the posi-

Table 3. Measured parameters and instrumentation; see Fig. 2 for instrument positions

\begin{tabular}{|c|c|c|c|c|}
\hline Site & Measurement & Parameter & Instrument & Sampling interval \\
\hline \multirow[t]{3}{*}{ All } & $\begin{array}{l}\text { Continuous } \\
\text { Instantaneous }^{a}\end{array}$ & $\begin{array}{l}\text { Air temperature and relative humidity } \\
\text { Air temperature and relative humidity }\end{array}$ & $\begin{array}{l}\text { Gemini Tiny Tag Plus } \\
\text { Rotronic OP100A }\end{array}$ & $5 \mathrm{~min}$, averaged to $1 \mathrm{~h}$ means \\
\hline & & Wind speed & $\begin{array}{l}\text { Swema SWA03 } \\
\text { (hot wire anemometer) }\end{array}$ & $1 \mathrm{~s}$, averaged to 5 min means \\
\hline & & Surface temperature & FSI Thermopoint 62 & \\
\hline \multirow[t]{2}{*}{$\mathrm{UoM}^{\mathrm{b}}$} & Continuous & Air temperature and relative humidity & Vaisala 50Y & $1 \mathrm{~h}$ \\
\hline & Continuous & Global radiation & Skye 1110 pyranometer & $1 \mathrm{~h}$ \\
\hline
\end{tabular}


tioning of the probes is shown in Fig. 2). The difference between the fixed and the instantaneous measurements was within $\pm 1 \mathrm{~K}$ at all sites including the Pettah (DMP) site, where the logger had to be placed above a lawn in a nearby courtyard (see Fig. 2) where the H/W ratio differed from the street.

Moreover, instantaneous measurements of surface temperatures and wind speed were taken at pedestrian level at each site. The temperatures of the pavements, street and adjacent facades were measured with an infrared thermometer. The wind speed was measured with a directionally independent wind sensor. The instantaneous measurements were taken between April 30 and May 8, 2003 primarily in the morning and in the afternoon.

Table 4. Official weather data obtained from weather stations Colombo city, Ratmalana, Katunayake. Radiation only measured at Columbo city; wind speed and direction measured at Colombo city and Katunayake

\begin{tabular}{|lcc|}
\hline Parameter & $\begin{array}{c}\text { Measuring } \\
\text { height }(\mathrm{m})\end{array}$ & $\begin{array}{c}\text { Sampling } \\
\text { interval (h) }\end{array}$ \\
\hline Air temperature & 1.5 & 1 \\
Relative humidity & 1.5 & 1 \\
Rainfall & & 1 \\
Cloud cover & & 3 \\
Global radiation & 4 & 1 \\
Wind & 4 \\
\hline
\end{tabular}

Table 5. Weather types and rainfall at Colombo. $\mathrm{C}=$ 'clear', $\mathrm{PC}=$ 'partly cloudy', OC = 'overcast'. Only rainfall events above $5 \mathrm{~mm}$ have been included. Note that the night of April 30 means the night between April 30 and May 1. Rainfall data $(\mathrm{mm}$; duration in $\mathrm{h})$ is from Colombo city weather station

\begin{tabular}{|lccccccc|}
\hline Date & \multicolumn{3}{c}{ Day } & \multicolumn{4}{c|}{ Night } \\
& Sky & Rainfall & Sky & \multicolumn{2}{c|}{ Rainfall } \\
& & $(\mathrm{mm})$ & $(\mathrm{h})$ & & & $(\mathrm{mm})$ & $(\mathrm{h})$ \\
\hline Apr 30 & PC & 6 & 5 & OC & & \\
May 1 & C & & & C & & \\
May 2 & C & & & PC & & \\
May 3 & C & & & C & 5 & 1 \\
May 4 & C & & & PC & 17 & 4 \\
May 5 & PC & & & C & & \\
May 6 & OC & 83 & 8 & PC & & \\
May 7 & PC & 9 & 1 & OC & & \\
May 8 & C & & & C & & \\
May 9 & PC & & & PC & & \\
May 10 & OC & 36 & 6 & PC & & \\
May 11 & OC & 42 & 7 & OC & & \\
May 12 & OC & & & OC & 55 & 9 \\
May 13 & OC & 10 & 3 & OC & 12 & 3 \\
May 14 & C & & & OC & & \\
May 15 & PC & & & C & & \\
May 16 & PC & & & PC & & \\
\hline
\end{tabular}

\subsubsection{Reference data}

In addition to the fixed stations, official weather data were collected from 3 first-order weather stations maintained by the Sri Lankan Department of Meteorology: Colombo city station, Ratmalana Domestic Airport and Katunayake International Airport, see Table 4 and Fig. 1. The first is located in a residential district within the city limits. The airports, Ratmalana just south of the city and Katunayake some $25 \mathrm{~km}$ north of downtown Colombo, are representative of the suburban conditions of the CMR. Data from these synoptic stations were made available during the measurement/calibration period (April 30 to May 16, 2003)

\section{RESULTS AND DISCUSSION}

\subsection{Classification of days}

The measurement period included weather conditions ranging from fairly clear days to overcast days, sometimes with rainfall. In order to categorize the measurement period into synoptic weather types, official weather data from the Colombo city station was used. Cloud cover and global radiation data were used to categorize the measurement period into clear, partly cloudy and overcast days and nights. As expected, the cloud cover was extensive during the whole measurement period and there were no really clear days according to standard definitions (less than 2 octas cloud cover, see e.g. Jonsson 2005). In this study, the definition of 'clear' was $<5$ octas, 'partly cloudy' 5 to 7 octas and 'overcast' $>7$ octas. These groups corresponded to the following daily global solar radiation ranges: $>5000 \mathrm{Wh} \mathrm{m}^{-2}, 2000$ to $5000 \mathrm{Wh}$ $\mathrm{m}^{-2}$ and $<2000 \mathrm{Wh} \mathrm{m}^{-2}$ respectively. Using this definition, 6 days and 5 nights were categorized as 'clear', 6 days and 6 nights were 'partly cloudy' and 5 days and 6 nights were 'overcast'. During the measurement period, sunrise was around 06:25 h, solar transit at $12: 37 \mathrm{~h}$ and sunset around 18:50 h local standard time (LST). As such, 07:00 to 19:00 h LST was classified as 'day' and 20:00 to 06:00 h LST as 'night'. The classification of days together with rainfall events is shown in Table 5.

\subsection{Air temperature}

The urban-rural air temperature differences during the measurement period were significant. Under 'clear' conditions, differences were slightly greater by day than by night. The intra-urban differences were much larger during the day than at night. 


\subsubsection{Daytime temperatures at the fixed stations}

During clear and partly cloudy days, both heat and cool islands were observed at the urban sites. On clear days, the intra-urban differences reached $7 \mathrm{~K}$ and most of the urban sites were cooler than the rural station (Fig. 4). Such a cool island phenomenon has been noted in several tropical cities (e.g. Nichol 1994, 1996a,b, Jonsson 2005). In the case of Colombo, the reason for the cool islands is likely to be a combination of shading by buildings and sea breeze cooling. Moreover, the urban-rural and intra-urban differences were significant on partly cloudy days (Fig. 5).

The effect of urban morphology is illustrated by the tendency of the maximum temperatures (defined in this study as the temperature at $14: 00 \mathrm{~h} \mathrm{LST}$ ) to decrease with increasing H/W ratio. Fig. 6 shows this relationship for clear days, but the trend also exists to a lesser degree on partly cloudy days. The warmest site, NUG, has the lowest H/W ratio, while the coolest sites have higher $\mathrm{H} / \mathrm{W}$ ratios. A probable reason is that less solar radiation is absorbed at street level for larger $\mathrm{H} / \mathrm{W}$ ratios. The results of this study agree with Ahmed (1994) who found a similar trend in Dhaka, Bangladesh during the hot-humid summer. Studies in hot-dry climates also show the same trend, e.g. Bourbia \& Awbi (2004) and Johansson (in press).

The clearest evidence of the sea breeze effect is the difference between the BoC site and the GRB and DMP sites. All 3 sites are roughly equidistant from the

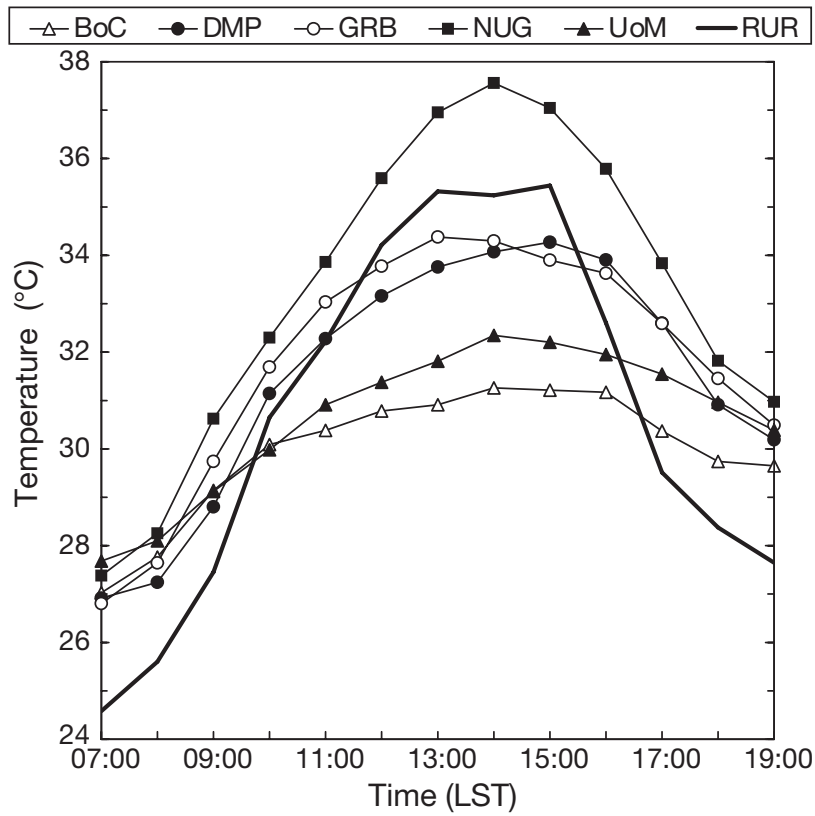

Fig. 4. Average temperatures of the fixed urban canyon stations on 'clear' days (5 days). RUR: rural station. See Fig. 2 for further abbreviations sea, but GRB and DMP are much warmer. The reason is likely to be the blocking of the sea breeze by buildings. The sea breeze is also a contributing factor to the difference between the cool BoC site and the warmest site, NUG, which is about $4 \mathrm{~km}$ inland. Evidence of the sea breeze effect can also be found at the UoM site where the temperature at roof level, which the sea breeze is probably able to reach, is lower than at street level. It is not known how deep into the city the sea breeze penetrates, but the results indicate that there is little sea breeze penetration at street level, due to the presence of dense development. Nieuwolt (1966) had a similar finding in Singapore. The results of this study agree with the findings of Jonsson (2005)

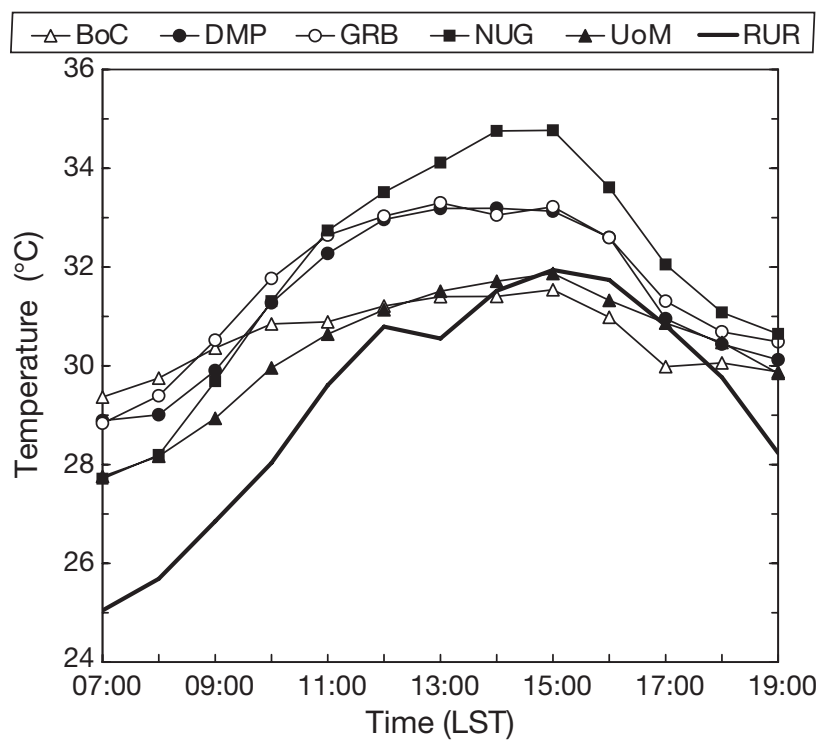

Fig. 5. Average temperatures of the fixed urban canyon stations on 'partly cloudy' days (4 days). RUR: rural station. See Fig. 2 for further abbreviations

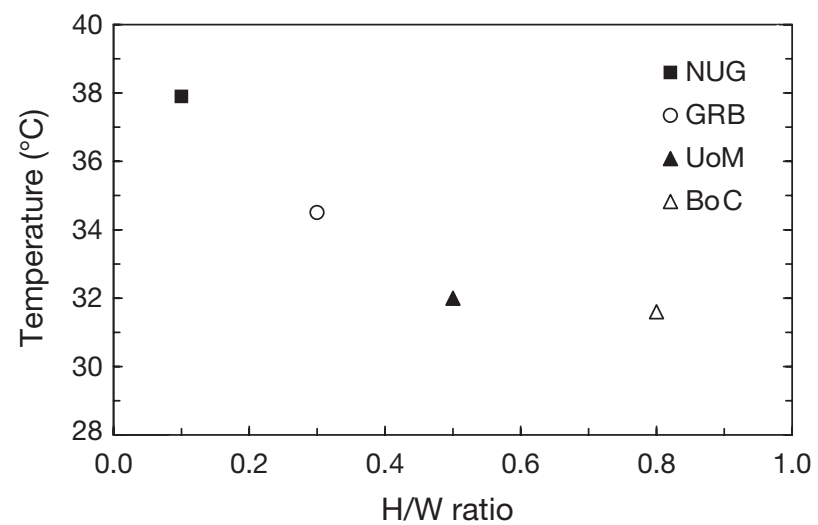

Fig. 6. Relationship between average daily maximum temperatures (at 14:00 h LST) and the H/W ratio on clear days (5 days). See Fig. 2 for abbreviations. DMP site not shown because $\mathrm{H} / \mathrm{W}$ ratio of courtyard is not known 
in hot-humid Dar es Salaam, Tanzania, where the sea breeze creates a daytime cool island during the intermonsoon period (the period when the sea breeze effect was most profound). The effect of sea breeze on the city climate was also noted by Saaroni et al. (2000) in Tel-Aviv, Israel. Places close to the sea, or where the urban morphology allowed the sea breeze to penetrate, were cooler than the rest of that city. As the $\mathrm{H} / \mathrm{W}$ ratio as well as the distance and openness to the sea differ between the sites, it was not possible to estimate the relative effect of each factor on the cool island.

The ground cover may also influence intra-urban differences. The only site where permeable ground exists (the graveled road at the UoM site) is among the coolest by day; the other sites all have ground cover of impervious, dense materials such as concrete and asphalt.

The temperature differences between the fixed stations were negligible on overcast days. This is to be expected since solar radiation is limited and the sea breeze is weak. During rainfall caused by afternoon thunderstorms, the temperature could drop drastically by 8 to $9 \mathrm{~K}$. This phenomenon, which is mainly due to downdraft of cool air from high altitudes was found by Nieuwolt (1966) in Singapore.

\subsubsection{Nocturnal UHIs at the fixed stations}

A small, but distinct, UHI developed during clear and partly cloudy nights. Fig. 7 shows the nocturnal UHIs for 'clear' nights. The magnitude, about $3 \mathrm{~K}$, is smaller than normally found in mid-latitude cities for the same city size and sky-view factor (SVF; the average SVF for the urban sites was 0.5), but is similar to observations in East Asian cities (Oke et al. 1991). The results also agree with results from other hot-humid, coastal cities such as Singapore (Tso 1996) and Dar es Salaam (Jonsson 2005). The probable reasons for the small UHI are: high rainfall (which leads to high soil moisture at the rural site), high humidity in the air and

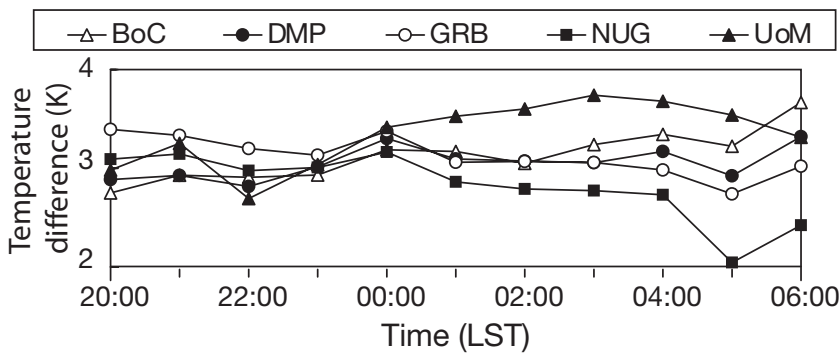

Fig. 7. Average urban-rural temperature differences between fixed stations on 'clear' nights (4 nights). See Fig. 2 for abbreviations high cloud cover (both of which cause high sky emissivity) (see e.g. Oke et al. 1991).

As expected, there is a general tendency of the UHI effect to diminish with increased cloud cover, although this relationship was not always clear. Variations in wind speed did not seem to influence the magnitude of UHI. However, it must be noted that the measured wind speeds were very small, especially within builtup areas (in general $<2 \mathrm{~m} \mathrm{~s}^{-1}$, see below).

As can be seen in Fig. 7, there were small differences in UHI intensity between the urban sites. No clear relationship between urban geometry, expressed either as $\mathrm{H} / \mathrm{W}$ ratio or SVF, and UHI could be found, especially in the evening soon after sunset. Instead, 3 of the sites had the highest UHI intensity at the end of the night just before sunrise, and at this time (06:00 h LST) there was a tendency for the UHI to increase with decreasing SVF. However, at the other sites, NUG and GRB, the maximum UHI was just after sunset, especially following clear days with high solar radiation. The reason could be that these sites, which have a low H/W ratio and ground covers of dense, dark surface materials, absorb and store high amounts of heat during the day which is then released after sunset. The degree of intraurban variation diminished with increased cloud cover, overcast conditions virtually wiping out the differences.

\subsection{Solar radiation and surface temperatures}

The maximum global solar radiation for 'clear' sky conditions - the instantaneous value at 13:00 h LST reached $900 \mathrm{~W} \mathrm{~m}^{-2}$. On overcast days, the maximum was only 400 to $500 \mathrm{~W} \mathrm{~m}^{-2}$. Only small variations were found between the official values of the Colombo city station and the UoM site, where the global radiation was measured.

The surface temperatures of facades, pavements and streets varied considerably, depending on whether surfaces were exposed to direct solar radiation or not. Under clear sky conditions, dark (i.e. low albedo) horizontal surfaces such as concrete paving and asphalt had temperatures between 50 and $60^{\circ} \mathrm{C}$ in the early afternoon. The difference between nearby sunlit and shaded spots was between 10 and 20 K. Facades were colder than horizontal surfaces in general, especially around noon when differences reached 10 to $20 \mathrm{~K}$. The reason was the smaller angle of incidence resulting in lower solar radiation flux density, but the fact that some facades had lighter colors than the streets and sidewalks must also be noted. Even so, the facades were 5 to $15 \mathrm{~K}$ warmer than the air temperature during sunny conditions. These findings agree with Nakamura \& Oke (1988), Nichol (1996a), Pearlmutter et al. (1999) and Ali-Toudert et al. (2005). 
The higher surface temperatures have implications on human comfort in urban areas. Johansson \& Emmanuel (in press) show that the mean radiant temperature of a person on the sunny side of a street canyon will be very high and consequently the thermal comfort of this person will be very poor.

\subsection{Humidity}

The relative humidity $(\mathrm{RH})$ varied between sites, but was on average around $75 \%$ during the day and around $90 \%$ at night. However, the $\mathrm{RH}$ on clear days dropped to $55 \%$ at the warmest sites (Fig. 8). The average vapour pressure (VP) calculated according to DIN 4108 (DIN 1981) for the Colombo city station was $32 \mathrm{hPa}$ during the measurement period. Fig. 9 shows the average VP of the urban sites compared with the rural site for clear and partly cloudy days. There was

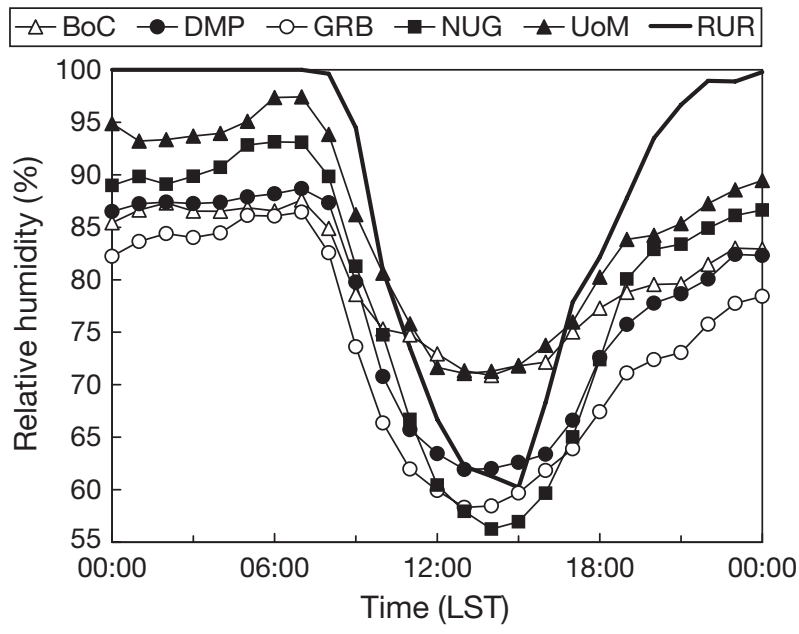

Fig. 8. Average relative humidity on 'clear' days (5 days). RUR: rural station. See Fig. 2 for further abbreviations

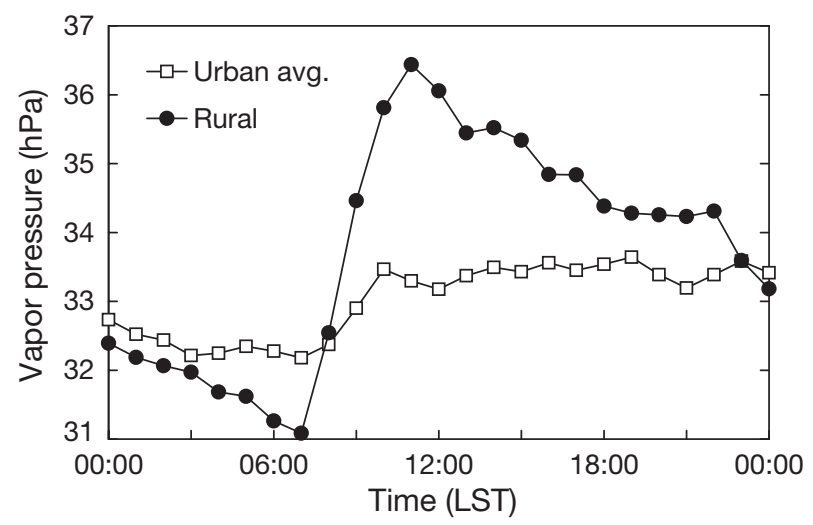

Fig. 9. Average vapour pressure for 'clear' and 'partly cloudy' days (9 days) evidence of urban moisture excess (UME) during the night. However, the rural VP rose sharply whereas the urban increase was moderate shortly after sunrise, when the convection process started. The latter situation is likely to be due to less evapotranspiration and lower convection within the urban areas (Oke 1987, Mayer et al. 2003). The rural VP decreased in the afternoon, but the urban VP remained almost constant due to decreased evaporation. This is most likely the result of a low ventilation rate within the urban canyons (Oke 1987). Other studies have also found a nocturnal UME with an urban-rural VP difference (Jáuregui \& Tejeda 1997, Holmer \& Eliasson 1999, Mayer et al. 2003). Although VP was lower in urban than in rural areas by day, the humidity levels in this study are sufficiently high to have a negative impact on thermal comfort, as the evaporative cooling potential of the human body decreases at high humidity (Givoni 1998).

\subsection{Wind}

Wind data reported from the official weather stations showed low wind speeds - on average $<2 \mathrm{~m} \mathrm{~s}^{-1}$ at the city station - and varying wind directions during the first 2 wk of the measurement period. This was followed by higher wind speeds, more or less consistently from the SW, at the end of the period. Thus, the measurement campaign seems to have covered the last $2 \mathrm{wk}$ of the inter-monsoon period.

The wind roses at 15:00 $\mathrm{h}$ and 00:00 $\mathrm{h}$ LST for the first $2 \mathrm{wk}$ of the measurement period are shown in Fig. 10. Although the Colombo city station is situated some $2 \mathrm{~km}$ inland, there is a SW afternoon sea breeze. At night, however, wind speeds are very low and no prevailing direction can be discerned.

A limited number of instantaneous measurements indicates that wind speeds are higher in shallow canyons (NUG, GRB) and at the site open to the sea (BoC) than in the deeper canyons (DMP, UoM). The wind speeds at the BoC site were higher than the centrally situated Colombo city station, whereas wind speeds at the deeper canyons of DMP and UoM were lower.

\section{CONCLUSIONS}

The microclimate was measured at 5 urban sites in Colombo, Sri Lanka and at a nearby rural site. The measurements were carried out during the intermonsoon period in May 2003, when temperature and humidity are at their peak and wind speeds are low. This period is also characterized by high rainfall and a high degree of cloud coverage. 


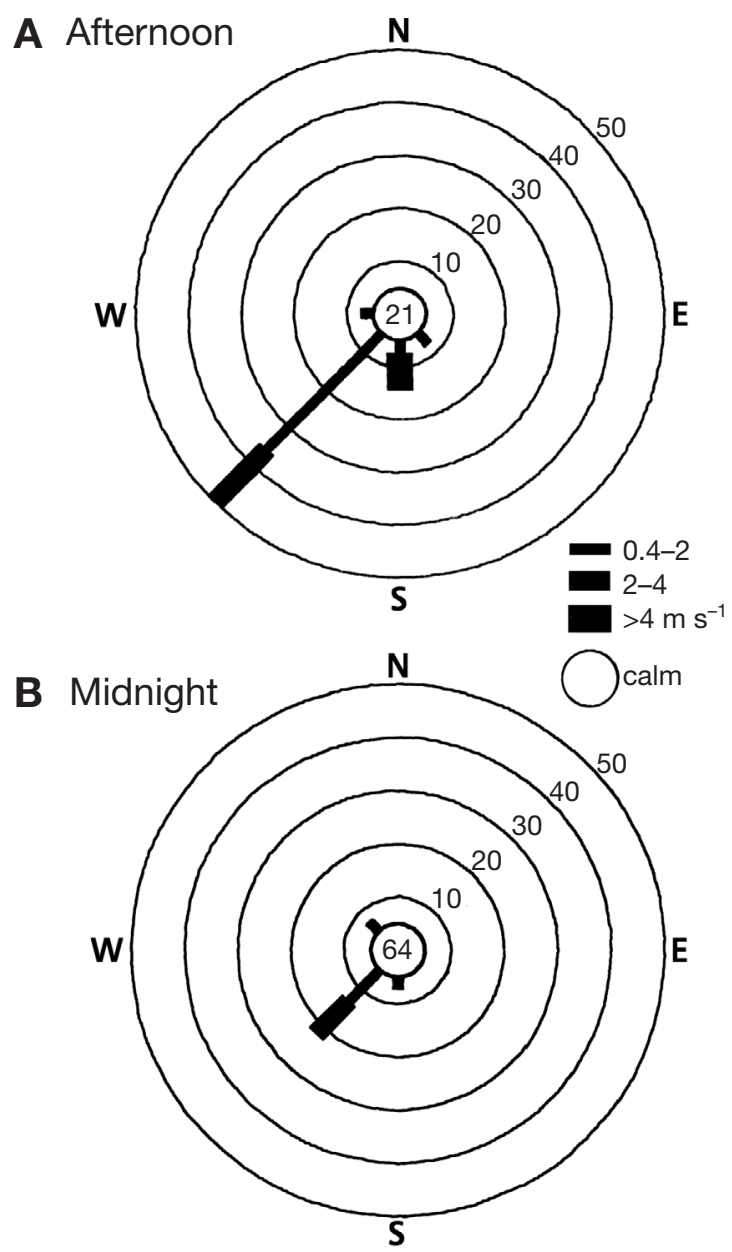

Fig. 10. Wind roses, based on 3-hourly observations, at (A) 15:00 h and (B) 00:00 h LST at the Colombo city weather station for the first $2 \mathrm{wk}$ of measurement period (April 30 to May 13, 2003). Numbers in wind roses are \%

The temperature differences between the urban sites reached $7 \mathrm{~K}$ on clear days in spite of the relatively wet period of measurement. Urban morphology had a significant impact on daytime air temperatures; the maximum daily temperature decreased with increasing H/W ratio. There was also evidence of a sea breeze effect; sites open to the sea were significantly cooler than other urban sites. In contrast to the daytime variations, only small intra-urban temperature differences were found at night. It is likely that both the intra-urban and urban-rural differences will be bigger during drier seasons.

The solar radiation was intense on clear days; consequently, sunlit surfaces became very hot, up to $20 \mathrm{~K}$ above air temperature. Wind speeds were low in general, but tended to decrease with increasing $\mathrm{H} / \mathrm{W}$ ratio.

The urban planning and design implications of these findings could contribute to the development of climate-sensitive urban design guidelines on building morphology, street layout and landscape control in Colombo and other cities with similar climate. This study showed that

- The use of high H/W ratios in urban design may be favorable, as this leads to lower daytime air temperatures and more shade at street level.

- Sea breeze penetration into the city should be facilitated by opening up the coastal strip. Currently, medium-rise buildings act as a barrier along much of the coast and intersections consist mainly of narrow streets.

- Horizontal shading is necessary to provide shade to people and urban surfaces around solar noon. This could be achieved by planting shade trees and building pedestrian arcades.

Further studies are needed to develop adaptation strategies that could improve the microclimate at street level in different parts of the city. These could include detailed microclimatic measurements combined with questionnaire surveys to explore comfort preferences of the local population. There is also a need for an evaluation of different climate-sensitive design concepts both by measurements and by computer simulations. Additionally, studies are needed to explore different ways to create shade in the urban environment without reducing air movement. A variation in building height is likely to be beneficial, since this stimulates air movement.

Acknowledgements: We thank the Ministry of Environment and Natural Resources, Sri Lanka (support to R.E. under the Climate Change Enabling Activity Project, Grant No. 03/06/253/64) and the Swedish International Development Co-operation Agency (Sida) (support to E.J.) for financial support. We also thank the owners of premises in which measurement stations were located, and the Department of Meteorology, Colombo, for providing official weather data. Digitized land cover information was provided by the Survey Department of Sri Lanka. The help provided by Mr. P.K.S. Mahanama, Department of Town and Country Planning, University of Moratuwa, Sri Lanka (digital images) and Ms. K.P.C. Kothalawala of the Department of Architecture, University of Moratuwa, Sri Lanka (urban morphology information in CAD file format) is gratefully acknowledged. The manuscript was proof-read by A. Semadeni-Davies and M. Emmanuel. The line drawings were produced by M. Rückert.

\section{LITERATURE CITED}

Adebayo YR (1991) 'Heat Island' in a humid tropical city and its relationship with potential evaporation. Theor Appl Climatol 43:137-147

Ahmed KS (1994) A comparative analysis of the outdoor thermal environment of the urban vernacular and the contemporary development: case studies in Dhaka. In: Etzion Y, Erell E, Meir IA, Pearlmutter D (eds) Proc 11th Int Conf Passive Low Energy Architecture (PLEA). Ben-Gurion Univ of the Negev, Sede-Boker, p 341-348

Ali-Toudert F, Djenane M, Bensalem R, Mayer H (2005) Out- 
door thermal comfort in the old desert city of Beni-Isguen, Algeria. Clim Res 28:243-256

Arnfield AJ (1990) Canyon geometry, the urban fabric and nocturnal cooling: a simulation approach. Phys Geogr 11: $220-239$

Arnfield AJ (2003) Two decades of urban climate research: a review of turbulence, exchanges of energy and water, and the urban heat island. Int J Climatol 23:1-26

Bourbia F, Awbi HB (2004) Building cluster and shading in urban canyon for hot dry climate. Part 1: Air and surface temperature measurements. Renew Energ 29:249-262

DIN (Deutsche Industrie Norm) (1981) DIN 4108: Thermal insulation in buildings. Beuth Verlag, Berlin

Eliasson I (2000) The use of climate knowledge in urban planning. Landsc Urban Plann 48:31-44

Emmanuel R (1997) Summertime heat island effects of urban design parameters. PhD Thesis, University of Michigan, Ann Arbor

Emmanuel R (2005) An urban approach to climate-sensitive design: strategies for the tropics. Spon Press, London

Givoni (1998) Climate considerations in building and urban design. Van Nostrand Reinhold, New York

Harrison GA, Gibson JB (eds) (1976) Man in urban environments. Oxford University Press, Oxford

Holmer B, Eliasson I (1999) Urban-rural vapour pressure differences and their role in the development of urban heat islands. Int J Climatol 19:989-1009

Jáuregui E (1997) Heat island development in Mexico City. Atmos Environ 31:3821-3831

Jáuregui E, Tejeda A (1997) Urban-rural humidity contrast in Mexico City. Int J Climatol 17:187-196

Johansson (in press) Influence of urban geometry on outdoor thermal comfort in a hot dry climate: a study in Fez, Morocco. Build Environ

Johansson E, Emmanuel R (in press) The influence of urban design on outdoor thermal comfort in the hot, humid city of Colombo, Sri Lanka. Int J Biometeorol

Jonsson P (2005) Urban climate and air quality in tropical cities. PhD Thesis, Earth Sciences Centre, Göteborg University, Göteborg

Lake JV, Bock GR, Ackrill K (eds) (1993) Environmental change and human health. Wiley-Interscience, Chichester

Matzarakis A, Rutz F, Mayer H (2000) Estimation and calculation of the mean radiant temperature within urban structures. In: de Dear RJ, Kalma JD, Oke TR, Auliciems A (eds) Biometeorology and urban climatology at the turn of the millenium. World Meteorological Organization, Geneva, p 273-278

Editorial responsibility: Helmut Mayer, Freiburg, Germany
Mayer H, Matzarakis A, Iziomon MG (2003) Spatio-temporal variability of moisture conditions within the urban canopy layer. Theor Appl Climatol 76:165-179

Nakamura Y, Oke TR (1988) Wind, temperature and stability conditions in an east-west oriented urban canyon. Atmos Environ 22: 2691-2700

Nichol JE (1994) A GIS-based approach to microclimate monitoring in Singapore's high-rise housing estates. Photogramm Engineer Remote Sens 60:1225-1232

Nichol JE (1996a) High-resolution surface temperature patterns related to urban morphology in a tropical city: a satellite-based study. J Appl Meteorol 35:135-146

Nichol JE (1996b) Analysis of the urban thermal environment with LANDSAT data. Environ \& Plann B 23:733-747

Nieuwolt S (1966) The urban microclimate of Singapore. J Trop Geogr 22:30-37

Oke TR (1981) Canyon geometry and the nocturnal urban heat island: comparison of scale model and field observations. Int J Climatol 1:237-254

Oke TR (1987) Boundary layer climates. Methuen, London

Oke TR (1988) Street design and urban canopy layer climate. Energy Build 11:103-113

Oke TR (2004) Initial guide to obtain representative meteorological observations at urban sites. World Meteorological Organization, Geneva

Oke TR, Taesler R, Olsson LE (1990/91) The tropical urban climate experiment (TRUCE). Energy Build 15-16:67-73

Oke TR, Johnson GT, Steyn DG, Watson ID (1991) Simulation of surface urban heat islands under 'ideal' conditions at night. Part 2: diagnosis of causation. Boundary-Layer Meteorol 56:339-358

Pearlmutter D, Bitan A, Berliner P (1999) Microclimatic analysis of 'compact' urban canyons in an arid zone. Atmos Environ 33:4143-4150

Saaroni H, Ben-Dor E, Bitan A, Potchter O (2000) Spatial distribution and microscale characteristics of the urban heat island in Tel-Aviv, Israel. Landsc Urban Plann 48:1-18

Terjung WH, Louie SSF (1973) Solar radiation and urban heat islands. Ann Assoc Am Geogr 63:181-207

Todhunter PE (1990) Microclimatic variations attributable to urban-canyon asymmetry and orientation. Phys Geogr 11: $131-141$

Tso CP (1996) A survey of urban heat island studies in two tropical cities. Atmos Environ 30:507-519

WCED (World Commission on Environment and Development) (1987) Our common future. Oxford University Press, Oxford

Submitted: November 19, 2005; Accepted: March 14, 2006

Proofs received from author(s): April 7, 2006 